\title{
Migrantes 2.0. Funciones y potencialidades del uso de Internet por las colectividades de migrantes en Argentina
}

\author{
Cecilia Eleonora Melella* \\ (cemelella@gmail.com)
}

Artículo de investigación recibido el 29/11/2014 y aprobado el 20/04/2015

Cómo citar este artículo:

MELELLA, Cecilia Eleonora (2015). "Migrantes 2.0. Funciones y potencialidades del uso de Internet por las colectividades de migrantes en Argentina”. En: Trans-pasando Fronteras, núm. 7, pp. 61-84. Cali, Colombia: Centro de Estudios Interdisciplinarios, Jurídicos, Sociales y Humanistas (CIES), Facultad de Derecho y Ciencias sociales, Universidad Icesi.

DOI: $10.18046 /$ retf.i7.1775

\section{Resumen}

Este artículo forma parte de las investigaciones realizadas en mi tesis sobre las actitudes lingüísticas generadas en la mitad oeste de la Península Ibérica y la frontera con Portugal (Extremadura-Alentejo/ Beira). El artículo pretende dar muestra del cambio de actitud positiva que se está sufriendo en esta zona rayana debido a las buenas relaciones de los estados ibéricos a pesar de las asimetrías que existen. Se visualizan, además, las perspectivas positivas donde se muestra una renovada relación que

* Doctora en Ciencias Sociales por la Universidad de Buenos Aires (UBA), Magister en Comunicación y Cultura (UBA), Licenciada y Profesora en Educación Superior en Ciencias de la Comunicación (UBA). Docente de Ciclo Básico Común (UBA). Becaria posdoctoral del Consejo Nacional de Investigaciones Científicas y Técnicas (CONICET). 
rompe con algunas de las más llamativas visiones negativas heredadas del pasado. Un ejemplo bien podría ser término lingüistico "vivir de espaldas" relacionado con el país al otro lado de los bordes. De esta forma es como se perciben, dentro del imaginario de una nación y, del imaginario político y cultural, las llamadas fronteras. En ocasiones, viene a ser una metáfora de la transgresión, pero las fronteras no siempre cumplen ese papel. La frontera del oeste Ibérico bien podría ser el caso de una raya llena de convenios bilaterales, de trabajo en equipo y buenas relaciones. Un cambio surgido en las últimas décadas gracias al Estatuto de Autonomía de la región extremeña y del interés que los ciudadanos han demostrado por la cultura del otro.

\section{Palabras clave}

Espacio de frontera, actitud lingüística, lenguas en contacto.

\section{Introducción}

La prensa migrante en la Argentina data del siglo XIX y funcionó, principalmente, como medio de expresión y de participación cívica alternativa frente a la imposibilidad de intervención política directa de los colectivos migratorios en el país. Asimismo, se ha constituido como un medio de circulación de saberes e intereses de estos grupos, así como un recurso de conformación de identidades y de visibilización en la sociedad receptora (Melella, 2013a). Este tipo de prensa producida se manifestó en un período posterior a la declaración de la Independencia de 1816. Luego, tras la afirmación del principio de libre expresión de las ideas sancionado por la Constitución de la Nación Argentina de 1853, se inició un ciclo próspero para la publicación de diarios, periódicos y revistas (Cibotti, 1994; Oteiza, 2010).

La inmigración fue uno de los factores que contribuyó a las transformaciones estructurales en el país al participar en su modernización e inserción en el mercado mundial. Asentados en la nueva tierra, los grupos migratorios fundaron y instituciones de índole asociativa dentro de la sociedad civil como Sociedades de Socorros Mutuos, asociaciones deportivas, mutuales ligadas al trabajo, asociaciones culturales y políticas, etcétera (Devoto, 2004). Las publicaciones comunitarias tomaron ímpetu dentro de este contexto, pues cumplían con el objetivo de integrar, comunicar y conectar a los inmigrantes de diversas colectividades hacia el seno de las mismas y establecer vínculos con la sociedad de destino (Garabedian, Szir, y Miranda; 2009). ${ }^{1}$

1 Por ejemplo, Mariana Baravalle (2007) asegura que debido a que en 1869 comienza a regir la Ley de Ciudadanía, este nuevo escenario político requería la naturalización de los inmigrantes y la inscripción en el registro 
Pasado el período de asentamiento, los periódicos comunitarios desaparecieron o centraron su agenda en la difusión cultural de actividades de las distintas colectividades. Sin embargo, esta práctica periodística fue retomada en la década de 1990 por los migrantes latinoamericanos como respuesta a los discursos estigmatizantes de los que eran objeto y que circulaban en los medios de comunicación masivos. Los inmigrantes de países latinoamericanos, en especial los peruanos, bolivianos y paraguayos fueron construidos por los medios desde la amenaza y utilizados como el chivo expiatorio que encauzaría los males de la nación. En este contexto, la prensa migrante se propuso la construcción de un discurso alternativo que presentara la "voz" de estos colectivos. Los tres periódicos más representativos de las colectividades latinoamericanas debido a su antigüedad y permanencia en el tiempo, así como por su cantidad de ejemplares son: Gaceta del Perú, de la colectividad peruana, fundado en 1991; Paraguay Ñane Reta, de la colectividad paraguaya, fundado en 1993 y Renacer, de la colectividad boliviana, fundado en 1999. ${ }^{2}$ Las funciones de los periódicos excedieron la denuncia de la primera etapa y, retomaron aquellas desplegadas por la prensa europea. De tal forma, se propusieron informar a los connacionales sobre sus países de origen y destino, oficiar de medio solidario y de asistencia jurídica, social, cultural, constituirse como espacios de conformación identitaria y lazos de cohesión interna, así como recursos de visibilidad en las sociedades receptoras (Melella, 2012).

Pasada la primera década del segundo milenio, los periódicos de migrantes desembarcaron en la Web a través de páginas y de redes sociales virtuales como Facebook. Renacer inauguró su edición Renacer online y su cuenta de Facebook. Le siguieron Paraguay Ñane Reta y Gaceta del Perú. Asimismo, se diversificaron en la red Internet otros medios de comunicación, asociaciones civiles, culturales y políticas de migrantes. El pasaje al universo de las nuevas TIC, abre un universo casi sin límites, disímil, efímero, con bajos costos, acceso ilimitado desde una computadora o un teléfono inteligente. En consecuencia, el objetivo de este trabajo consiste en analizar el pasaje de la prensa de

electoral. La prensa gráfica de los diferentes colectivos migratorios actuaba como vínculo entre estos migrantes y el Estado nacional. Por otro lado, la prensa de los grupos se financiaba con recursos disímiles como aportes de socios, suscripciones, publicidades, venta en quioscos, entre otras.

2 Los tres rondan entre 5.000 y 10.000 ejemplares. Además tienen versión digital en página Web y cuentas de Facebook. Renacer se dejó de emitir en papel en mayo de 2014. 
migrantes al universo de Internet, analizar las funciones sociales de estos nuevos medios de comunicación y desentrañar sus potencialidades para estos colectivos específicos.

Para dar cuenta de esta relación entre migración, prensa gráfica y uso de las TIC, desde el punto de vista metodológico, se trabajó con la prensa gráfica y digital, así como con las páginas Web de asociaciones de las colectividades latinoamericanas. Estos objetos heterogéneos fueron analizados a partir de una perspectiva cualitativa que combinó un enfoque interdisciplinario. Hemos trabajado con un corpus compuesto por periódicos de migrantes (en su versión en papel y online) y por páginas Web y cuentas de Facebook de asociaciones culturales, civiles y políticas de diversos colectivos migratorios latinoamericanos asentado en la Argentina. Realizamos una selección de dichos periódicos, portales y cuentas de Facebook y estudiamos, por un lado, su superficie textual desde una perspectiva semiótico-comunicacional que contempló el análisis de discurso y contenido. Por otro lado, trabajamos con programas informáticos (Navicrawler y Gephi) ${ }^{3}$ que nos permitieron graficar y dar cuenta de la conectividad de esto sitios. ${ }^{4}$

\section{Cambios cualitativos de las redes virtuales: los grandes diarios en la Web}

Fundada sobre los principios de multimedialidad, hipertextualidad e interactividad, Internet generó un nuevo espacio de comunicación (Albornoz, 2007; ¿cuales? Al menos se deben nombrar dos o tres autores para decir "entre otros" entre otros). La multimedialidad permite integrar en un mismo soporte diversos formatos: texto, audio, video, gráficos, fotografías, animaciones. La hipertextualidad consiste en una forma multidireccional (no lineal) de estructurar y acceder a la información en los entornos digitales a través de enlaces. La interactividad implica que los miembros de la audiencia pueden iniciar y desarrollar acciones de comunicación con el medio y con otros usuarios.

3 El programa Navicrawler permite examinar la estructura y los enlaces de cada uno de los sitios Web relevados y crear una base de datos que importamos al programa Gephi. Éste nos permitió graficar, visualizar e interpretar la estructura y distribución de las asociaciones de migrantes en el ciberespacio.

4 Para realizar este artículo utilizamos los resultados obtenidos en investigaciones anteriores que desarrollaron puntillosamente el análisis textual de los periódicos de inmigrantes en la Argentina (La prensa migrante en la Argentina. Recurso de visibilidad y construcción de identidades: El caso del periódico Renacer, de y para la colectividad boliviana) y su pasaje al universo de Internet (Migración y tecnologías de la información y la comunicación (TIC). De la prensa gráfica a las redes virtuales como espacios de construcción identitaria de los migrantes de países andinos en la Argentina). Incluir detalladamente estos análisis excede las pautas editoriales de este artículo. 
Estos principios de Internet, de fuerte impacto en las relaciones sociales, hanf fomentado fomentaron en los años noventa la apertura a la red por parte de los principales diarios del mundo. La industria de la prensa gráfica ha venido experimentando un período de reconversión a otros formatos tecnológicos desde los años cincuenta y su pasaje al universo de Internet en la década del noventa la ha transformado en un agente de primer orden en el desarrollo de la esfera pública de la Sociedad de la información (Castells, 1995 y 1999). Guallar Delgado (2006) propone tres criterios para la diferenciación de la presencia de los medios en la Web: a) según el tipo de información que ofrecen (si son generales o especializados); b) según el ámbito geográfico al que van dirigidos (estatal, autónomo, local, etcétera) y c) según el origen (si la publicación digital proviene de un medio de comunicación tradicional o ha nacido directamente de Internet). Los periódicos online proceden de medios de comunicación tradicionales, motivo por el cual su pasaje a la red implica la reconversión al espacio digital de ciertas lógicas inherentes a la prensa gráfica.

Históricamente, entre 1993 y 1995 se inició la incursión de la prensa gráfica al universo digital cuando un puñado de empresas informativas estadounidenses como Compuserve, America OnLine, Information Exchange decidieron aventurarse a Internet y concibieron los primeros sitios Web de información general ${ }^{5}$ (Rost, 2003 y Albornoz, 2007). En esta primera etapa los periódicos online contaban con recursos precarios que sólo permitían trasladar a las versiones electrónicas el contenido de la edición papel en una actualización diaria. Entre los principales objetivos se privilegiaba experimentar con las TIC y establecer nuevos canales para llegar a nuevos lectores, participar de la convergencia multimedia, disponer de un nuevo medio de información de bajo costo (poco personal, sin gasto de papel, impresión y distribución) y favorecer una nueva fuente de ingresos publicitarios (Díaz Noci 1996). Entre 1994 y 1995 se produjo un salto exponencial de las editoras de prensa a Internet. Esta segunda etapa estuvo marcada por el gran crecimiento del número de sitios Web de entidades de todo tipo. ${ }^{6}$ Sin embargo, varios es-

5 El primer sitio Web de información diaria fue The Chicago Tribune en 1992 a través de la red de America Online (Albornoz, 2007).

6 Según Díaz Nosty: "En 1994, tan sólo 20 periódicos ofrecían sus ediciones digitales en Internet. A mediados de 1995, la cifra de periódicos diarios, semanales y especializados ascendía a 78, pero seis meses más tarde, a finales de año, eran ya 471. En 1996 se alcanzaron las 1920 cabeceras, valor que en junio de 1997 llegó, según el 
tudiosos afirman que los grandes diarios digitales no representaron un negocio rentable. Publicar en un diario online no liberaba a las empresas periodísticas de la edición impresa. Por lo tanto, las empresas mediáticas tuvieron que contar con atractivos que volcaran al público a leer la edición online, aunque esto implicase el riesgo de que el éxito de la red repercutiese en la caída de ventas de la edición tradicional.

Por su parte, entre los recursos más importantes que se contemplan en el pasaje de la prensa en papel a la online se encuentra la incorporación de los tres grandes sistemas de signos: sonidos, imágenes y letras (Piscitelli, 2010; entre otros). A diferencia de la prensa impresa, cuya particularidad consiste en un original que es reproducido en un determinado número de copias en papel y tinta, las editoras de prensa online elaboran productos (contenidos) simbólicos únicos e inmateriales que pueden contener todas las morfologías textuales (texto escrito, imágenes fijas, imágenes en movimiento y sonidos), remarcando su carácter multimedial. Además, la renovación de contenidos no se realiza diariamente, sino que responde a la agenda (al acontecimiento noticioso) y requiere de una actualización permanente. Otra diferencia de los periódicos online es su carácter gratuito (sólo acceso a una conexión), su nula restricción geográfica, su función de archivo y su potencialidad para la participación del lector/usuario (interactividad e hipertextualidad). No obstante, resulta interesante que los diarios masivos en Internet como Clarin.com o Elmundo.es priman la difusión unidireccional de contenidos y servicios (punto a masa) aunque potencialmente cuentan con las herramientas para una interacción mediatizada parte del lector/usuario.

Asimismo, a partir de los años noventa, se fundaron comunidades virtuales en las que sus miembros participan del intercambio de informaciones y opiniones según diversos intereses. Autores como Quintar (2007) y Finquelievich et al. (2007) indican que estas ciber-comunidades revitalizan y expanden las colectividades sociales existentes. No obstante, la referenciación de estas organizaciones en la Web permanece inscripta sobre la dimensión local, regional o nacional. Las colectividades de migrantes andinos en la Argentina utilizan las TIC para comunicarse, transmitir información, difundir actividades 
culturales, construir identidad y hasta potenciar el ejercicio de la ciudadanía política. La aparición de la plataforma Facebook ha incrementado el uso por parte de estos grupos de las TIC y la apropiación de un espacio en la red de redes.

\section{Un paso adelante: la galaxia Facebook}

La red Facebook es considerada una plataforma, un espacio múltiple en el cual convergen diversos contenidos y formatos (Scolari, 2008), un médium digital (Piscitelli, Adaime y Binder, 2010), un mutante digital que está en constante transformación (López y Ciuffoli, 2012) y un sistema operativo sobre el que se desarrollan nuevas aplicaciones y servicios en la red Internet. Asimismo, Facebook ha desencadenado posturas diversas y controversiales dentro del campo intelectual. Algunos pensadores sostienen que esta plataforma conforma un espacio narcisista que favorece el entretenimiento banal y la exposición innecesaria de la vida privada. Otros afirman que Facebook hace realidad la utopía del espacio libre de ataduras que puede complementar y hasta suplir otros espacios de socialización. Lo cierto es que Facebook conforma el sitio con más usuarios en la historia de Internet, pues es utilizado por más del 10\% de la población mundial, es decir, si fuera un país sería el tercero más grande del mundo luego de China (1340 millones de habitantes) e India (1170 millones de habitantes). ${ }^{7}$ Así, en 2012 los usuarios activos superaron los 1000 millones: de cada diez personas del planeta, una está en Facebook. ${ }^{8}$ Además, la plataforma es responsable del 52\% del contenido que se comparte online. En Latinoamérica las estadísticas siguen esta tendencia con el 96\% de la población total en línea que visita asiduamente la red social. Brasil, México, Argentina, Colombia, Venezuela, Chile y Perú son los siete países con más usuarios activos de Facebook. En enero de 2013, la Argentina, que posee más de 20 millones de usuarios activos, ${ }^{9}$ encabezó el ranking de consumo de redes sociales con 9,8 horas al mes en promedio. ${ }^{10}$

7 La Nación, 1 de enero de 2012. http://www.nacion.com/2012-02-01/Tecnologia/Facebook-podria-serel-tercer-pais-del-mundo-por-su-cantidad-de-usuarios.aspx

8 La Nación, 5 de octubre de 2012, ver: http://www.lanacion.com.ar/1514453-mil-millones-de-personasde-todo-el-mundo-ya-tienen-su-perfil-de-facebook

9 La Nación, http://www.lanacion.com.ar/1558461-facebook-tiene-20-millones-de-usuarios-en-la-argentina.

10 "Facebook no sólo "rankea" bien en la Argentina en cantidad de usuarios. Según un estudio de la consultora especializada Comscore, los argentinos encabezan el ranking de consumo de redes sociales con 9,8 horas 


\section{Imagen 1}

Mapeo de amistades del mundo

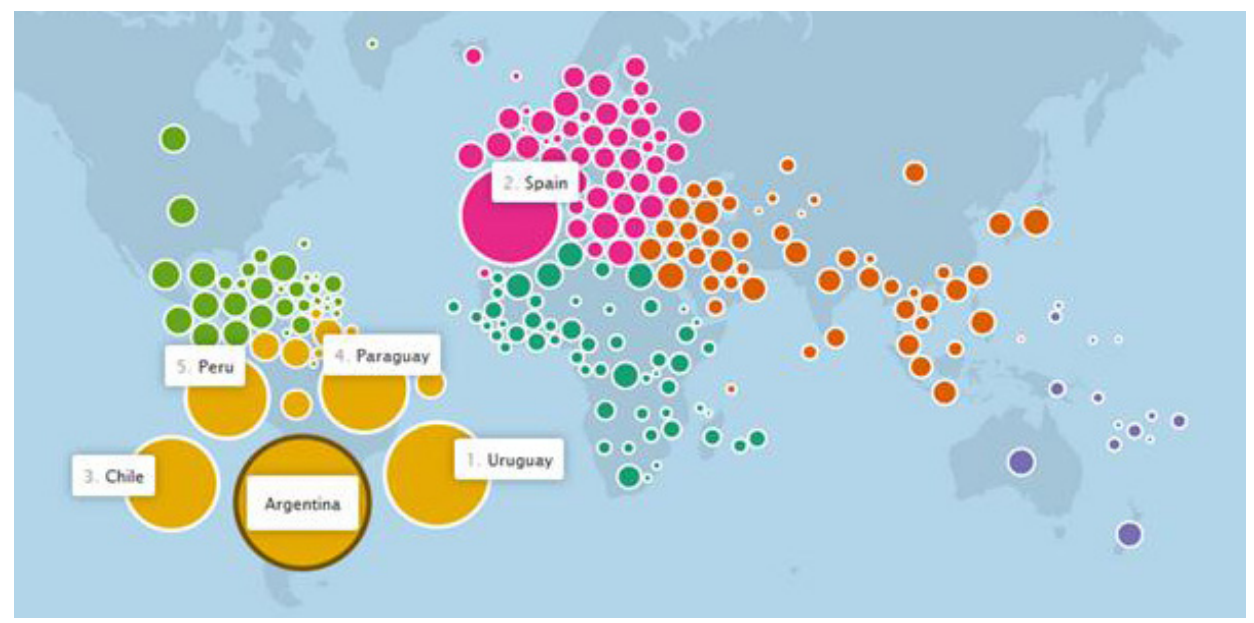

Fuente: Diario Clarín, 10 de septiembre de 2012

Teniendo en cuenta la Imagen 1, se observa que la Argentina acrecentó su número de usuarios y enfatizó sus vínculos con países sudamericanos (Uruguay, Chile, Paraguay y Perú) y con España. Podemos inferir que este incremento en la vinculación con estas naciones de la región se debe a la cantidad de residentes y migrantes pertenecientes a esos grupos que viven en el país.

\section{Una historia reciente}

Facebook es una plataforma creada por un grupo de estudiantes de la Universidad de Harvard, Cambridge, Massachusetts, Estados Unidos, en el año 2004, entre los que se destacaban Mark Zuckerberg, Chris Hughes, Dustin Moskovitz y Eduardo Saverin. Su objetivo era que los alumnos de esa casa de estudios se conectaran entre sí. En el año 2005 esta red se extendió hacia las escuelas medias de los Estados Unidos y allí comenzó su expansión. Entre los años 2006 y 2007, Facebook se consolidó como una red pública 
y gratuita con la apertura del servicio a mayores de trece años. También, en esos años, comenzó a generar aplicaciones que permitían compartir (share) e insertar (embed) contenidos provenientes de otros sitios de Internet.

Entre 2008 y 2010 la red se conformó como masiva y abierta. El sitio se tradujo a 21 lenguas en 2008 y llegó a 100 en 2011. Paralelamente se produjo el lanzamiento de Facebook Connect, una aplicación que permitió utilizar la identidad de Facebook en otros espacios de la Web, es decir, llevar su red social a los sitios y páginas de los que el usuario participaba. ${ }^{11}$ Asimismo, la creación del botón "Me gusta" permitió conectar a Facebook con otros sitios a través de la calificación de los gustos del usuario, convirtiéndose en una de las primeras acciones que tendieron a exhibir el grafo social. A partir de 2010, Facebook concretó la experiencia de navegación social y personalizada a través de la implementación del Protocolo Open Graph. Esta aplicación permite el acceso a la base de datos de los usuarios -que incluye información cualitativa sobre gustos y preferencias-y autoriza la integración de cualquier sitio de Internet a Facebook posibilitando la socialización de contactos ("amigos"), de productos, de servicios y de contenidos que se visiten en la red. ${ }^{12}$

\section{Un camino de continuidades y rupturas}

Se pueden señalar dos características centrales de Facebook. Por un lado, es un espacio convergente de diversos contenidos y formatos. Por otro lado, cambió las formas de comunicar y participar en Internet (Piscitelli, Adaime y Binder, 2010). Como representante privilegiado de la Web 2.0, esta plataforma representa un salto cualitativo con respecto a la Web 1.0. En esta última, las posibilidades de participar e interactuar eran reducidas,

11 Se realiza mediante el uso de tres herramientas de la plataforma: el botón compartir, los fan box (son como los "Me gusta" de las páginas en Facebook sobre contenidos o personajes públicos. Desde la web externa te puedes hacer fan sin necesidad de visitar el espacio en Facebook) y widgets de comentarios (son módulos de Facebook situados en otras web en los que puedes hacer comentarios instantáneos sobre el contenido de esa página). Ver: http://blog.ticketea.com/index.php/2010/11/que-es-facebook-connect-y-para-que-sirve/

12 El Protocolo Open Graph habilita la interacción de cualquier sitio Web con Facebook. Esto es: a través de una integración sencilla el sitio se "transforma" en un "objeto" de Facebook, por lo cual, los usuarios se pueden suscribir al sitio a través de la aplicación "me gusta" y éste les podrá mandar actualizaciones automáticas. Lo interesante es que los administradores de estos nuevos sitios pueden acceder a las estadísticas de su comunidad para monitorear el comportamiento de los suscriptores. Los sitios y aplicaciones sociales que utilicen este protocolo pueden acceder al grafo social, es decir, a información, gustos e intereses de los usuarios y compartirlo con los demás (López y Ciuffoli, 2012). 
pues el acceso a las tecnologías y los costos de equipos y de conexión eran elevados. Además, quien publicaba en la Web necesitaba conocimientos específicos de programación y protocolos de transferencia de archivos.

Por el contrario, la Web 2.0 incrementó las posibilidades de participación a personas con escasos conocimientos sobre informática (amateurización de la producción) por medio de dos procesos: producción y publicación de contenidos por parte del usuario y participación más activa de las audiencias. Esta caída de las barreras cognitivas se logró a través de la rigidez de una arquitectura homogénea y estandarizada. Por ejemplo, todos los perfiles de Facebook son iguales, no hay una personalización del espacio propio, no se permiten cuentas Premium (superiores) y los casilleros para publicar están predefinidos.

Asimismo, Facebook reemplazó el lenguaje técnico de los sistemas informáticos por la lengua de la vida cotidiana, más cercana a las relaciones indiciales, a través del uso de metáforas de conexión ("agregar amigos", "etiquetar", "me gusta”, "hacerse fan”) y metáforas de publicación ("muro", "comentario", "me gusta", "escribir notas"). Al mismo tiempo, se configura como un espacio convergente al incluir plataformas y herramientas preexistentes en la Web. Esta característica de Facebook permite que se establezcan puentes de familiaridad con los medios anteriores. Así, estas posibilidades posicionan a la plataforma por fuera de la lógica de los medios masivos de comunicación tradicionales (punto a masa) y la ubican como aquella que posibilita la colaboración activa de usuarios (muchos a muchos).

\section{Cuadro 1}

Continuidades y rupturas

\begin{tabular}{|c|c|}
\hline Continuidades & Rupturas \\
\hline $\begin{array}{l}\text { - } \quad \text { Red social. } \\
\text { Plataforma de publicación personal: se } \\
\text { puede publicar llenando campos como en } \\
\text { el blog. } \\
\text { - Audiencia como flujo fragmentado, } \\
\text { expandido y autónomo. } \\
\text { Horizontalidad. }\end{array}$ & $\begin{array}{l}\text { - Las acciones del usuario quedan } \\
\text { registradas: "Usar es publicar" (se acentúa } \\
\text { la red, permite la reconstrucción del grafo } \\
\text { social y función del archivo ) } \\
\text { Aumenta la participación en las } \\
\text { publicaciones de otros contactos a través } \\
\text { de herramientas como "Me gusta", } \\
\text { "Comentar", "Compartir", etcétera. } \\
\text { - Se vuelve más confusa la división entre } \\
\text { usuarios y creadores o autores y lectores } \\
\text { (no hay jerarquías) } \\
\text { Se incrementa la comunicación en tiempo } \\
\text { real. }\end{array}$ \\
\hline
\end{tabular}

Fuente: elaboración propia 


\section{Inmigrantes online}

Dentro del contexto migratorio internacional también se ha experimentado el pasaje de los medios gráficos de inmigrantes al uso de la Web. De acuerdo a la clasificación sobre este pasaje propuesto por Guallar Delgado (2006), los medios de comunicación de migrantes en la Web provienen de un medio de comunicación tradicional, pues resulta frecuente la presencia de los periódicos destinados a las comunidades inmigrantes en el ciberespacio a través de páginas Web y /o cuentas de Facebook. En la Argentina, apreciamos una vasta presencia de las colectividades migratorias en la Web. Los inmigrantes no cortan afectiva ni comunicativamente con su tierra natal, por lo cual, la posibilidad de leer (en tiempo real) la prensa de sus países de origen o la prensa migrante en destino conectan, aún más, el aquí y el allá y fortalecen el paradigma del transnacionalismo (Vertovec, 2001; Portes, 2005). Las investigadoras españolas Gómez Escalonilla y Campos Zabala (2009) afirman que existen dos tipos de medios de inmigrantes en red: los periodísticos y los medios de servicio. En España, estas autoras observan que los más frecuentes son los medios de servicio -páginas Web, comunidades virtuales, páginas oficiales o de asociaciones- que proveen al recién llegado las direcciones útiles de organizamos oficiales o de asociaciones de migrantes, información sobre trámites migratorios o sobre esparcimiento. La presencia de los periódicos en la Web sigue los patrones de los periódicos "étnicos" que informan desde la perspectiva de la propia comunidad migrante y con una manera de leer las informaciones desde su propia cultura, con su propia lengua y estilo lingüístico (Martínez Pastor y Santín Durán, 2009).

Por su parte, Facebook potencia la instantaneidad y la interacción de las páginas Web con una estructura accesible y estandarizada. El quebranto de las limitaciones temporales va de la mano del traspaso de las fronteras espaciales. Facebook es un medio que tecnológicamente promueve las relaciones transnacionales porque en el ciberespacio la consignación real a un Estado o territorio queda la mayoría de las veces en un segundo plano (Goube, 2012). En este sentido, el contacto en tiempo real favorece el desarrollo superlativo de la cultura de los vínculos que permite al migrante estar conectado con su entorno social tanto en origen como en destino (Diminescu, 2011 y 2012). 
La difusión o planificación de noticias, de actividades culturales, de normativa migratoria y de experiencias no se circunscribe a los límites de espacio y tiempo humanos y atraviesa las fronteras territoriales. En el caso de los migrantes, la principal función pareciera ser el contacto con la familia, pero también es posible fomentar el vínculo con la diáspora, potenciar la circulación de información o la concreción de comunicación en red. Por ejemplo, Facebook permite "subir o postear" información (fotos, textos, video, links) de una forma más sencilla e instantánea. También, a partir de la opción "compartir" se puede poner en común la información que haya "subido" un "amigo". Esta aplicación exhibe y permite reconstruir la red (Melella, 2013b).

\section{Migrantes 2.0. De la prensa gráfica a la Web}

El pasaje al universo de Internet no implica rupturas con otras prácticas previas o paralelas, como la prensa gráfica, sino recuperaciones y resignificaciones. Así, las funciones que estableció la prensa gráfica de migrantes, tanto la europea del siglo XIX y como la latinoamericana de finales del siglo XX, adquirieron nuevas potencialidades en el ciberespacio que detallaremos a continuación.

\section{Medio de información y opinión}

En primer lugar, las TIC proporcionan más posibilidades para la información y el ejercicio de la opinión de los diferentes colectivos migratorios. Así, los migrantes pueden mantener los consumos mediáticos que tenían en su patria conformando aquello que Appaurai (2001) denominó "audiencia diaspórica". El consumo de medios de los países de origen en destino promueve la reconstrucción de sus identidades de evidente carácter trasnacional. En el caso de los medios de comunicación de migrantes, las TIC promueven (mediante los links) la intersección y reconfiguración de una textualidad entendida como red (Scolari, 2008) y admiten la producción y circulación de noticias locales (Melella, 2012).

Asimismo, la hiperextualidad y la interactividad dan lugar a una mayor participación por parte de los lectores/usuarios. Como ya señalamos, no se requiere demasiado dinero ni conocimientos específicos para contar con una página Web o una cuenta de Facebook. Este último intensifica la capacidad para compartir información y emitir opiniones de forma liberalizada por parte de los miembros de la comunidad. Recordemos que una de 
sus máximas predica “usar es publicar” (López y Ciuffoli, 2012). Igualmente, no dejamos de reconocer su carácter de medio cerrado y con mecanismos de control (Deleuze, 2005). Sin embargo, los medios de comunicación de migrantes disfrutan en Internet de un espacio que anima su crecimiento y diversificación, adoptado mayoritariamente por los colectivos más jóvenes. En el caso de los migrantes de países latinoamericanos en la Argentina, observamos la presencia en la Web de asociaciones y medios de prensa de las colectividades más asentadas, como los bolivianos, paraguayos y peruanos. No obstante, para las migraciones más recientes como las ecuatorianas y colombianas, Internet es el recurso por excelencia que posibilita la fundación de medios de información y opinión más allá de la reunión en el espacio offline. ${ }^{13}$

\section{Medio solidario y de servicios}

También, los periódicos en sus versiones digitales tienen como objetivo brindar un servicio a la colectividad. Las campañas solidarias, notificaciones sobre trámites y normativa migratoria, informaciones sobre ocio y esparcimiento conforman decisiones editoriales estratégicas para cada uno de los sitios. Por ejemplo, la asociación peruana en la Argentina Casa del Perú asume como misión la concreción de obras artísticas, culturales y de bienestar social para su comunidad. Por su parte, la razón de ser de la página Web Ecuatorianos en Argentina fue constituir un espacio que brindara información útil (transporte público, direcciones importantes, servicios inmobiliarios, universidades) para los ecuatorianos que arribaban a la Argentina para estudiar o trabajar.

\section{Fuentes histórico-documentales}

Dada su constitución tecnológica, la red virtual se conforma como una red social más transparente y presenta una mayor accesibilidad a la información. Facebook representa un caso eximio al permitir la reconstrucción del grafo de conectividad ("usar es publicar"). Estas condiciones de Internet posibilitan la constitución de un gran archivo. Como

13 Las migraciones más recientes como colombianos y ecuatorianos no poseen gran cantidad de asociaciones o instituciones en el espacio offline, sino que su gran mayoría son asociaciones virtuales que, por supuesto, materializan prácticas y actividades como convocatorias a elecciones, campeonatos de fútbol, eventos culturales y comerciales, entre otras. Por el contrario, las migraciones más arraigadas como los bolivianos, paraguayos y peruanos poseen más asociaciones e instituciones en el espacio offline que en el online. 
afirma Andreas Huyssen (2007), las TIC proporcionan una posibilidad de conservación de la información nunca antes vista en la historia, no obstante, ésta es de carácter inmaterial y corre el riesgo de perderse con mayor facilidad. Con todo, Internet se establece como una fuente histórico-documental, en tanto, acervo virtual de las prácticas culturales, sociales, políticas de las colectividades migrantes y brinda un recurso ante la inexistencia de un registro único en la mayor parte de estos grupos.

\section{Lazo de cohesión interna y establecimiento de comunidades virtuales}

Las ediciones virtuales pueden establecerse como lazos y/o nodos que contribuyen a la cohesión interna y al establecimiento de imaginarios dentro de los grupos. Recordemos que para Granovetter (1973), las comunidades o grupos que generan más conectividad son aquellos que gozan de una gran cantidad de puentes -lazos débiles- que los conectan con otros, pero que no requieren del contacto cara a cara. ${ }^{14}$ Internet aumenta esta capacidad de conexión al potenciar comunidades virtuales definidas por el establecimiento de redes y no por la proximidad física (Kollock y Smith, 2002). Algunos grupos, como los bolivianos, paraguayos y peruanos, se han organizado en torno a comunidades físicas existentes. Sin embargo, otros colectivos como los colombianos y ecuatorianos, cuyo número ha aumentado en los últimos años, poseen una visibilidad anclada en el espacio online más que en el offline. Por consiguiente, los periódicos en la Web y los sitios de asociaciones se conforman como lazos entre los distintos subgrupos de cada colectividad (asociaciones, individuos, medios de comunicación) en el espacio online y offline (Finquelievich, 1999).

\section{Recurso de visibilidad en el espacio online y offline}

La visibilidad se basa en la voluntad e intencionalidad de un actor de ser o hacerse visible, de exponer sus cultura y exhibir sus modos de vida (Baby-Collin, Cortes, Miret y Sassone, 2010). La prensa gráfica de migrantes, las asociaciones civiles y políticas, las festividades laicas y religiosas configuran espacios y prácticas que hacen visibles a estos grupos migratorios en las sociedades de destino. Las TIC trasladan esa visibilidad al ciberespacio y

14 Para Granovetter los lazos fuertes son aquellos que evidencian un contacto más asiduo, pero más restringido. 
la expanden hacia los espacios offline a través, por ejemplo, de la convocatoria de actividades deportivas, políticas culturales, comerciales, etcétera. Si bien, promueven acciones que se expanden al mundo internaútico y que traspasan las fronteras espacio-temporales, también conforman prácticas y relaciones concretas en el espacio local.

\section{Discurso alternativo y/o contra-informacional}

Los medios de comunicación hegemónicos pueden invisibilizar aquello que cuestiona su influencia. Tal como señalamos en la introducción, la prensa gráfica de los migrantes latinoamericanos surgió como respuesta a esta estigmatización y su objetivo principal fue la puesta en circulación de un discurso alternativo que condensara el punto de vista que aquellos "que no tenían voz" dentro de la palestra mediática hegemónica representada por los oligopolios como el emblemático Grupo Clarín -propietario de los principales diarios, emisoras de radio y canales de TV de la Argentina-. Los periódicos más representativos de las colectividades latinoamericanas en la Argentina como Renacer, Gaceta del Perú y Paraguay Ñane Reta, a través de su diseño gráfico y la construcción de la agenda, configuran un discurso diferente al de los medios masivos que condensa las inquietudes y problemáticas de cada colectividad. Así, se conforman como medios alternativos al instaurar una opción frente al sistema dominante y/o contra-informacionales al proveer una lectura crítica desde el punto de vista del subalterno (Simpson Grinberg, 1981; Vinelli y Rodríguez Esperón, 2004). Por ejemplo, sus agendas se componen principalmente de temáticas vinculadas a la denuncia de discriminación y xenofobia, la intervención en el espacio político, la divulgación de la cultura de cada comunidad y las noticias sobre los países de origen.

\section{Herramienta para la participación política}

Por otra parte, la red Internet complementa a los periódicos de migrantes en la tarea de difundir un discurso alternativo y de concretar acciones políticas diversas. Recordemos que en la Argentina hacia finales del siglo XIX, a las colectividades extranjeras les era vedada la participación política y la prensa era el organismo elegido por las élites de las diversas comunidades para resolver conflictos y/o concertar acuerdos con el Estado nacional. En la actualidad, los debates en torno a la ampliación de ciudadanía política a 
los extranjeros y el ejercicio del voto desde el exterior fomentaron en las colectividades el interés por el ejercicio de derechos civiles, sociales y políticos en las sociedades de origen y destino (Imagen 3). Internet es un espacio que, debido a su bajo costo de comunicación y su carácter reticular, posibilita la coordinación de acciones en grupo. De este modo, se convierte en una herramienta que proyecta tácticas de construcción de poder con un mayor alcance para los grupos tradicionalmente en desventaja como es el caso de los migrantes de países latinoamericanos (Tilly, 2010).

\section{Imagen 2}

Llamado a la participación política
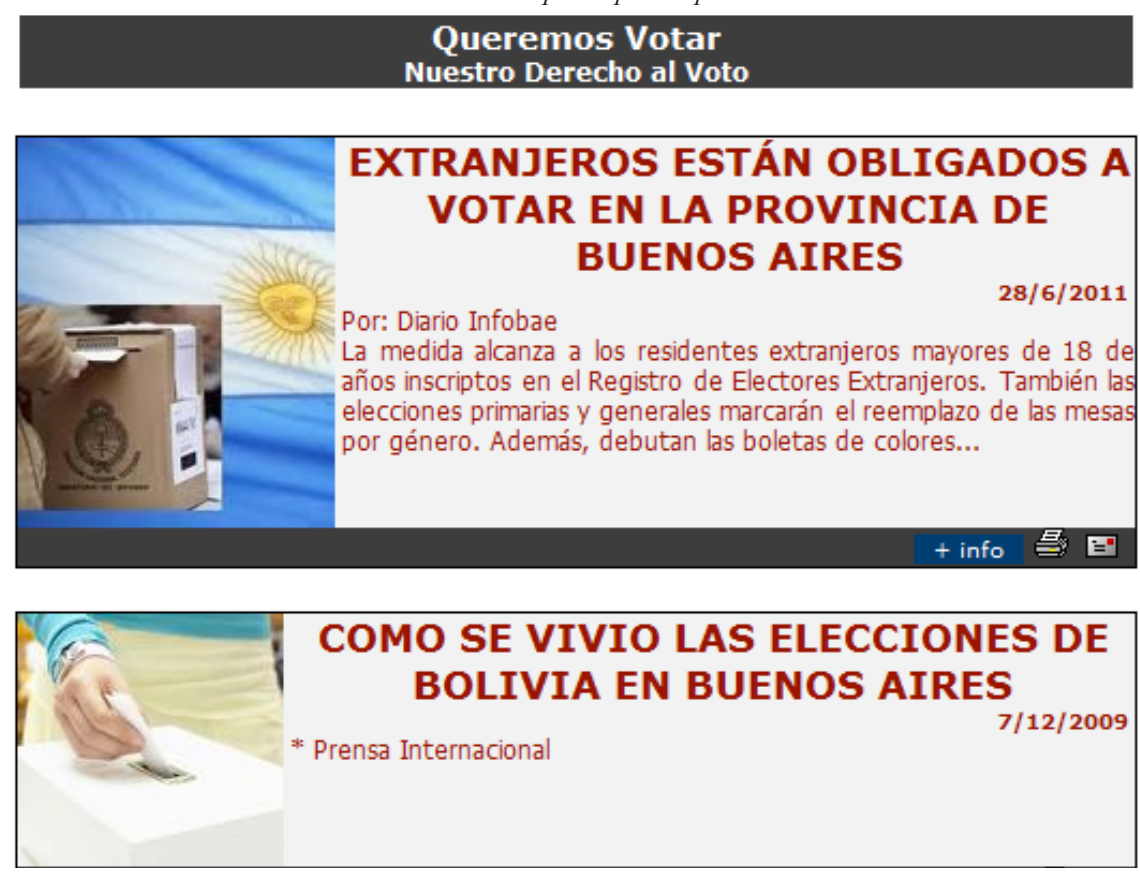

Fuente: Página Web de la colectividad boliviana en Argentina (www.comunidadboliviana.com.ar)

\section{Construcción de identidades virtuales}

Dado que el pasaje al ciberespacio promueve la producción y de circulación de imaginarios referenciales de cada colectividad, podemos considerarlos espacios de conformación de identidades. Por consiguiente, en la Web conviven las categorías identificatorias tradicionales (etnia, nacionalidad, religión, género) con nuevas prácticas de referenciación representadas por 
las nuevas tecnologías. A partir de nuestro trabajo empírico hemos concluido que la alusión a los Estados-nación, las marcas etno-culturales, el reclamo de derechos, el fomento de lazos de cohesión y la intervención en el espacio local a través de prácticas y actividades concretas instauran las bases sobre las que se despliegan las identidades migrantes en Internet.

\section{Medio de conexión y/o comunicación diaspórico}

Por último, los tres principios fundadores de Internet (multimedialidad, hipertextualidad e interactividad) potencian hipervínculos entre las asociaciones, medios de comunicación e individuos de los diversos grupos migratorios. Internet fortalece la conformación de lazos que trascienden las fronteras territoriales y que van más allá del espacio simbólico conformado por el origen y el destino, permitiendo la dispersión hacia un espacio diaspórico (Ogan, 2001). Sin embargo, como también apuntamos, los sitios analizados generan lazos dentro de la sociedad receptora a partir de prácticas de intervención (campañas solidarias, actividades culturales, reclamo de derechos, entre otras) y construyen un espacio virtual anclado en la localidad (Cuadro 2).

\section{Cuadro 2}

Funciones y especificidad

\begin{tabular}{|l|l|}
\hline \multicolumn{1}{|c|}{ Funciones } & \multicolumn{1}{c|}{ Especificidad } \\
\hline Medio de información y opinión & $\begin{array}{l}\text { Información sobre los países de origen y la } \\
\text { comunidad en destino. }\end{array}$ \\
\hline Medio solidario y de servicios & $\begin{array}{l}\text { Información específica sobre la condición de } \\
\text { migrante (trámites migratorios, bolsa de trabajo, } \\
\text { ocio-esparcimiento, entre otros). }\end{array}$ \\
\hline Fuentes histórico-documentales. & $\begin{array}{l}\text { Acervo virtual de prácticas culturales, sociales y } \\
\text { políticas de los grupos migratorios. }\end{array}$ \\
\hline $\begin{array}{l}\text { Lazo de cohesión interna y establecimiento de } \\
\text { comunidades virtuales. }\end{array}$ & $\begin{array}{l}\text { Difusión online y offline de actividades cultura- } \\
\text { les, políticas, sociales. }\end{array}$ \\
\hline $\begin{array}{l}\text { Recurso de visibilidad en el espacio online y } \\
\text { offline. }\end{array}$ & $\begin{array}{l}\text { Visibilidad de actividades, prácticas, discursos } \\
\text { de cada grupo en el espacio online y offline. }\end{array}$ \\
\hline Discurso alternativo y/o contra-informacional. & $\begin{array}{l}\text { Construcción de discurso y agenda propios que } \\
\text { cuestionan el orden hegemónico. }\end{array}$ \\
\hline Herramienta para la participación política. & $\begin{array}{l}\text { Medio para el reclamo y ejercicio de derechos } \\
\text { en origen y destino. Ampliación de ciudadanía y } \\
\text { voto en el exterior. }\end{array}$ \\
\hline
\end{tabular}




\begin{tabular}{|l|l|}
\hline \multicolumn{1}{|c|}{ Funciones } & \multicolumn{1}{c|}{ Especificidad } \\
\hline Construcción de identidades virtuales & $\begin{array}{l}\text { Resignificación de categorías de identificación } \\
\text { tradicionales (género, nacionalidad, etnia, reli- } \\
\text { gión, entre otras) en el ciberespacio. }\end{array}$ \\
\hline Medio de conexión y/o comunicación diaspórico & $\begin{array}{l}\text { Diáspora virtual. Ampliación de la capacidad de } \\
\text { interconexión con connacionales. }\end{array}$ \\
\hline
\end{tabular}

Fuente: elaboración propia

\section{Conclusiones}

A lo largo de este artículo demostramos que resulta posible establecer una línea conductora entre las funciones desarrolladas por los periódicos de las colectividades europeas del siglo XIX y el uso de la Web por los migrantes contemporáneos. Medios de información y opinión, medios solidarios y de servicios a las colectividades, recursos de visibilización en las sociedades receptoras, espacios para la configuración y circulación de un discurso alternativo y herramientas para la participación política conformaron las principales tareas y actividades que, a lo largo de la historia, han desarrollado la prensa europea y latinoamericana y las páginas Web de migrantes.

Sin embargo, la reconversión de la prensa gráfica al uso de Internet problematiza y complementa estas funciones. En primer lugar, presenta el antagonismo entre el espacio offline (la vida real) y el espacio online (ciberespacio). Lejos de una visión monolítica que imagina estos ámbitos como divergentes, consideramos que ambos están inmersos dentro de la trama social que se solapa y auto-imbrica. La apropiación y uso de herramientas tecnológicas como Internet dispone un espacio que, lejos de ser conflictivo, propicia el desarrollo de tácticas de conformación del sentido en ambos espacios (online y offline). En segundo lugar, ciertas construcciones tradicionales como la identidad, la comunidad y la comunicación se resinifican dentro del espacio online y reconfiguran su ligazón con el offline.

Por su parte, Facebook, a partir de una estructura homogénea, estandarizada y sencilla, garantiza la participación de una mayor cantidad de usuarios. De este modo, se constituye como una herramienta privilegiada en la experiencia migratoria para el sostenimiento de vínculos subrayando si carácter de medio de conexión y comunicación diaspórico. Esta plataforma admite la formación y/o comunicación de diversas redes 
transnacionales, ya sean éstas afectivas, comerciales, culturales y políticas. También, debido a su bajo costo y su carácter instantáneo, permite articular (superando a los e-mails) acciones colectivas en diversos territorios o en el ciberespacio y propaga lazos (débiles) que constituyen redes más dinámicas. Así, las TIC se posicionan como una dimensión ineluctable a la hora de estudiar los procesos de conformación cultural, política y social de las migraciones contemporáneas.

\section{Bibliografía}

ALBORNOZ, Luis. (2007). Periodismo Digital. Los Grandes Diarios en la Red. Buenos Aires, Argentina: Editorial La Crujía.

APPADURAI, Arjun. (2001). La modernidad desbordada. Dimensiones culturales de la globalización. Buenos Aires, Argentina: Fondo de Cultura Económica.

ARMAÑAZAS, Emy, DÍAZ NOCI, Javier y MESO, Koldo. (1996). El periodismo electrónico. Información y servicios multimedia en la era del ciberespacio. Barcelona, España: Ariel Comunicación.

BABY COLLIN, Virginie; CORTES, Genevieve; MIRET, Naik y SASSONE, Susana. (2010).Visibilidad de la migración boliviana en Madrid, Barcelona, Buenos Aires: un análisis comparado. XII de Población española. Población y espacios urbanos. Facultad de geografia $i$ historia de la Universitat de Barcelona. Consultado el 12 de marzo de 2013 desde: http://www.ub.edu/congreso_poblacion/docs/actas.pdf

BARAVALLE, Mariana. (2007). "La prensa y la inmigración en la Biblioteca nacional." $2^{\circ}$ Encuentro de Bibliotecas de Colectividades. Consultado el 12 de marzo de 2013 desde http://www.iai.spkberlin.de/fileadmin/salalmdocs/La_prensa_y_la_inmigracion_en_la_Biblioteca_Nacional_Argentina_text.pdf

CASTELLS, Manuel. (1995). La Era de la Información. Vol. I. La Sociedad Red. Madrid, España: Alianza Editorial.

CASTELLS, Manuel. (1999). La Era de la Información. Vol. II. Economía, sociedad y cultura. Madrid, España: Alianza Editorial.

CIBOTTI, Ema. (1994). Periodismo político y política periodística. La construcción pública de una opinión italiana en el Buenos Aires finisecular. Entrepasados 7, 7-25

DEVOTO, Fernando. (2004). Historia de la Inmigración en la Argentina. Buenos Aires, Argentina: Ed. Sudamericana. 
DELEUZE, Gilles. (2005). Posdata a las sociedades de control. En Ferrer, C. (comp.), El lenguaje libertario. Antología del pensamiento anarquista contemporáneo (pp. 115122). La Plata, Argentina: Terramar.

DIAZ NOCI, Javier. (1996). "Conceptos en torno al periodismo electrónico interactivo multimedia". En Universidad del País Vasco. Consultado el 12 de septiembre de 2012, desde www.pd.lp.ehu.es/Website/Memoria/Docentes/Diaz\%20Noci/Textos/.../ donosti.htm

DIMINESCU, Dana. (2011). El migrante conectado. Por un manifiesto epistemológico. En Hernández, V., Mera, C. y Oteiza, E. (comp.), Circulación de saberes y movilidades internacionales: Perspectiva latinoamericana (pp. 201-216). Buenos Aires, Argentina: Biblos.

DIMINESCU, Dana. (2012). "E-Disporas Atlas. Exploration and Cartography of Diasporas in Digital Networks". En E-daporas Atlas. Consultado el 14 de mayo de 2014, desde www.interdisciplinary.net/attheinterface/wpcontent/uploads/2012/06/diminescudpaper.pdf

FINQUELIEVICH, Susana. (1999). "Del café de barrio a las redes electrónicas. Las comunidades virtuales como actores sociales en las ciudades". Revista Kairós, 4. Consultado el 12 de marzo de 2013 desde http://www.revistakairos.org/k04-d02.htm

FINQUELIEVICH, Susana y PRINCE Alejandro. (2007). El (involuntario) rol social de los cibercafés. Buenos Aires, Argentina: Dunken.

FORD, Aníbal. (1999). La marca de la bestia. Identificación, desigualdades e infoentretenimiento en la sociedad contemporánea. Buenos Aires, Argentina: Norma.

GARABEIDAN, Marcelo, SZIR, Sandra, y MIRANDA, Lida. (2009). Prensa argentina siglo XIX: imágenes, textos y contextos. Buenos Aires, Argentina: Teseo

GÓMEZ ESCALONILLA MORENO, Gloria y CAMPOS ZABALA, María Victoria, (2009). "Espacios de solidaridad en Internet: Webs para inmigrantes". En CCI Comunicaciones a Congresos. Consultado el 25 de noviembre de 2012, desde migraciones. ugr.es/omecia/pages/seminarios/textos/Inmigraci\%C3\%B3n\%20e\%20Internet.pdf.

GOUBE, Josephine. (2012). "When immigration meets innovation: immigrants 2.0." En Migrant's rights network. Consultado el 3 de junio de 2013, desde http://www.migrantsrights.org.uk/migration-pulse/2012/when-immigration-meets innovation-immigrant-20

GRANOVETTER, Mark. (1973). The strength of weak ties, American Journal of Sociology 78 (6), 1360 - 1380. 
GUALLAR DELGADO, Javier. (2006). "Prensa digital en 2006". En Anuario THINkEPi. Comsultado el 18 de octubre de 2012, desde http://www.thinkepi.net

HINE, Christine. (2004). Etnografia virtual. Barcelona, España: UOC.

HUYSSEN, Andreas. (2007). En busca del futuro perdido. Cultura y memoria en tiempos de globalización. Buenos Aires, Argentina: Fondo de Cultura Económica.

KOLLOCK, Peter y SMITH, Mark. (2002). Comunidades en el ciberespacio. Barcelona, España: UOC.

LÓPEZ, Guadalupe y CIUFFOLI, Clara, (2012). Facebook es el mensaje. Oralidad, escritura y después. Buenos Aires, Argentina: Ediciones La Crujía.

MARCOS RECIO, Juan Carlos y MUÑO MORÁN, María Victoria. (2000). Los nuevos significados del concepto documentación. Madrid, España: Editora Fragua.

MARTÍNEZ PASTOR, Edith y SANTÍN DURÁN, Marina. (2009). Publicaciones para inmigrantes: Estudio de las informaciones y la publicidad dirigidas a la comunidad inmigrante. Doxa Comunicación 9, 125-144.

MELELLA, Cecilia. (2012). La prensa migrante en la Argentina. Recurso de visibilidad y construcción de identidades: El caso del periódico Renacer, de y para la colectividad boliviana. Saarbrücken, Alemania: Editorial Académica Española.

MELELLA Cecilia. (2013a). "Migración y tecnologías de la información y la comunicación (TIC). De la prensa gráfica a las redes virtuales como espacios de construcción identitaria de los migrantes de países andinos en la Argentina." Tesis de Doctorado, Facultad de Ciencias Sociales, Universidad de Buenos Aires, Argentina.

MELELLA, Cecilia. (2013b). Migración y Tecnologías de la Información y de la Comunicación (TIC). La presencia de los periódicos de migrantes en Internet y los desafíos del análisis de las redes sociales virtuales. Cuadernos de H ideas, 7 (7), 1-18.

OGAN, Christine. (2001). Communication and Identity in the Diaspora: Turkish Migrants in Amsterdam and the Impact of Satellite Television. Lanhan, Estados Unidos: Lexington Books.

OTEIZA, Viviene. (2010). Prensa escrita y migraciones: una reflexión acerca de los periódicos de colectividades extrajeras a lo largo de un siglo y medio de historia argentina. En Oteiza Enrique (comp.), Patrones migratorios en América Latina (pp. 111-135). Buenos Aires, Argentina: EUDEBA.

PISCITELLI, Alejandro, ADAIME, Iván y BINDER, Inés. (2010). El proyecto Fa- 
cebook y la posuniversidad. Sistemas operativos sociales y entornos abiertos de aprendizaje. Buenos Aires, Argentina: Ariel/Fundación Telefónica.

PORTES, Alejandro. (2005). Convergencias teóricas y evidencias empíricas en el estudio del transnacionalismo de los inmigrantes. Migración y desarrollo, 4, 2-19.

QUINTAR, Aída. (2007). Redes sociales y comunidades virtuales. En Quintar, A; Calello, T y Aprea, G. (comps.) Los usos de las TICs. Una mirada multidimensional (pp. 71-85). Buenos Aires, Argentina: Prometeo.

ROBLES, José Mauel. (2009). Ciudadanía digital. Una introducción a un nuevo concepto de ciudadano. Barcelona, España: UOC.

ROST, Alejandro. (2003). "El periódico digital: características de un nuevo medio". En Red-acción, sitio web del Área Periodismo de la Facultad de Derecho y Ciencias Sociales, UNCOMA. Consultado el 01 de marzo de 2013, desde http://red-accion.uncoma. edu.ar/asignaturas/pd.htm

SCOLARI Carlos. (2008). Hipermediaciones. Elementos para una teoría de la comunicación digital interactiva. Barcelona, España: Gedisa.

Simpson Grinberg, Máximo. (1981). Comunicación Alternativa y Cambio Social. I: América Latina. Ciudad de México, México: UNAM.

TILLY, Charles. (2010). Los movimientos sociales, 1768-2008. Desde sus orígenes a Facebook. Barcelona, España: Crítica.

VERTOVEC, Steve. (2001). "Transnational social formations: Towards conceptual cross-fertilization". En University of Oxford. Consultado el 2 de mayo de 2013, desde http://www.transcomm.ox.ac.uk/working\%20papers/Vertovec2.pdf

VINELLI, Natalia y RODRÍGUEZ ESPERÓN, Carlos. (2004). Contrainformación. Medios alternativos para la acción política. Buenos Aires, Argentina: Ediciones Continente.

WINOCUR, Rosalía. (2007). Robinson ya tiene celular. México, México: Siglo XXI.

Documentos de prensa

"Tim O'Reilly, Facebook es un nuevo sistema operativo". En La información.com. consultado el 13 de mayo de 2014, desde http://blogs.lainformacion.com/con-noticiasde-facebook $/ 2011 / 11 / 22 /$ tim-o $\% \mathrm{C} 2 \% \mathrm{~B} 4$ reilly-\%E2\%80\%9Cfacebook-es-un-nuevo-sistema-operativo $\% \mathrm{E} 2 \% 80 \% 9 \mathrm{D} /$ 
"Facebook podría ser el tercer país del mundo por su cantidad de usuarios". En La Nación, 1 de enero de 2012. Consultado el 13 de mayo de 2014, desde http://www. nacion.com/2012-02-01/Tecnologia/Facebook-podria-ser-el-tercer-pais-del-mundo-porsu-cantidad-de-usuarios.aspx

"Mil millones de personas de todo el mundo ya tienen su perfil de Facebook". En La Nación, 5 de octubre de 2012. Consultado el 13 de mayo de 2014, desde http://www. lanacion.com.ar/1514453-mil-millones-de-personas-de-todo-el-mundo-ya-tienen-superfil-de-facebook

"Facebook tiene 20 millones de usuarios en la Argentina". En La Nación, 27 de febrero de 2013. Consultado el 13 de mayo de 2014, desde, http://www.lanacion.com. ar/1558461-facebook-tiene-20-millones-de-usuarios-en-la-argentina. 
